\title{
Trust, Social Support and Adaptation: A Study of International Students in Japan
}

\author{
Shaoyu Ye
}

\begin{abstract}
Research suggests that there are two kinds of trust, generalized trust and particularistic trust. This study focuses on international students studying in Japan and investigates the relationship between their generalized trust of others, the social support they receive from both Japanese people and same-language speakers, and their sense of acceptance (SOA). A self-reported questionnaire survey was conducted, producing 206 valid responses. Multiple regression analysis showed that the respondents' self-esteem, generalized trust of others, and social support from Japanese people and same-language speakers all had significant effects on SOA. Structural equation modeling analysis showed that self-esteem not only had strong direct effects on SOA, but also had strong effects on an individual's generalized trust of others, which had mediating effects on social support from Japanese people and on SOA. However, no similar mediating effect on SOA was detected when the social support was from the same-language speakers. Implications of the study's findings are discussed.
\end{abstract}

Index Terms-International students in Japan, trust, social support networks (SSN), sense of acceptance (SOA).

\section{INTRODUCTION}

Trust is fundamental to social life. It is said that trust is the belief of people in the good intentions of others - that is, the intentions of others not to do them harm, to respect their rights, and to carry out their obligations [1]. According to [1] and [2], there are two types of trust, generalized trust and assurance. Generalized trust is a general belief in human benevolence, suggesting that trustworthiness is an aspect of human nature and that most people can be trusted despite some exceptions. On the other hand, assurance is a trust that stems from secure relationships with particular others. When individuals form a strongly committed interpersonal relationship with another person, they are likely to trust that other person. However, rather than being based on a general belief in the benevolence of others, this type of trust is based on the sense of security that arises from knowledge about, and therefore predictability of, the specific person [3].

The two types of trust may have different roles in the formation and maintenance of social networks. Generalized trust encourages people to approach others to form social relationships. If most people are believed to be trustworthy and their good will can be assumed, then there should be no impediment to moving out of one's comfort zone-the particular interpersonal relationships that one feels committed to-and getting to know unfamiliar others to

Manuscript received March 18, 2018; revised June 12, 2018. This study was supported by JSPS KAKENHI Grant Number 17K17620.

Shaoyu Ye is with the Faculty of Library, Information and Media Science, University of Tsukuba, 3058550 Japan (e-mail: shaoyu@slis.tsukuba.ac.jp). create new social opportunities. Thus, generalized trust should affect one's behavior with unknown others, namely, strangers. For example, people with a higher level of generalized trust are more likely to cooperate with strangers compared to those with lower levels of generalized trust [4]. On the other hand, particularistic trust-assurance marked by emotional connectedness-may help people maintain social relationships. Once relationships are formed, people may need a sense of emotional connection with those others in order to maintain a secure and committed social relationship. Relationism is grounded in a sense of relatedness to particular known others. People with strong relationism may therefore act to maintain social relationships once they are formed. However, although relationism may tend to strengthen one's commitment to social relationships, it may not encourage people to seek new social opportunities by finding and forming new social relationships. The study reported in [5] compared the different roles of trust in Australia, Germany, UK, Japan and South Korea, and found that generalized trust had a positive relationship to network closure in all five countries; however, the study also found that generalized trust and relationism had different relationships to network homogeneity in the different cultures.

International students (ISs) who study abroad may feel strong assurance towards other ISs, especially those from the same country, since they are considered to be "in-group" members; they may have a lower level of generalized trust of others, especially local residents (hosts), who are "out-group” members due to cultural differences, language boundaries, communication behaviors, and so on. In addition, the cultural distance may be different among different countries [6]. Furthermore, [7] and [8] suggested that increasing communication with their hosts would be an effective way for ISs to better adapt to the Japanese culture. Forming stable and fruitful relationships with Japanese people is likely to lead to an enhanced ability to cope with stress and improve and accelerate adaptation. Such beneficial relationships are known as "social support networks" (SSN). SSN is a general psychological term that indicates personal relationships expected to provide both tangible and intangible support and promote intercultural adaptation. Studies suggested that including more Japanese people in their SSNs will help ISs acquire Japanese-style social skills, and therefore improve their intercultural adaptation. However, [9] indicated that, while face-to-face communication decreased the maladaptation of ISs, communication through voice calls, instant messaging or emails had no such effect, as communication with social networks via these means tended to include more same-language speakers than Japanese.

Regarding the ISs' social support received from others, [10] developed a scale for Chinese students in Japan 
involving four areas-academic, human relationship, emotional and environmental-cultural-and four typestangible, mental, directive, and informational. [11] indicated that differences related to period of stay were not significant, but differences in areas or types of support, or in the interaction of period of stay and types of support were all significant. [12] used three periods to examine the effect of received support on the adaptation of ISs: three months (the first period), nine months (the second period), and one year and nine months (the third period) after arrival in Japan. As a result, no differences in the amount of support received during the three periods were found, but adaptation was better during the third period compared the other two periods studied. It was suggested that providing more support to ISs during the critical early period is effective in facilitating adaptation. However, insofar as [7] indicated that support from Japanese hosts may have a greater effect than support from fellow foreigners, it would be appropriate to clarify the different effects of the two sources of support.

Finally, [13] indicated that motivation for self-esteem is an important factor in seeking social support and that receiving more support from others leads to an increased level of subjective well-being [14]. Thus, it is reasonable to believe that receiving more social support from Japanese people will result in a greater feeling of acceptance and make it easier for ISs to adapt.

Based on these findings and discussions, the present study investigates the model shown in Fig. 1. According to the model, a higher level of self-esteem should lead to a higher level of trust of others (path a), which, in turn, will have a positive effect on social support (path b) and sense of acceptance (SOA) (path c). Furthermore, it is supposed that the effects of receiving more social support will also lead to a higher level of SOA (path d), as will the direct effects of self-esteem (path e). The study also investigates possible differences in the way social support from Japanese people and same-language speakers affects SOA (path d).

\section{METHOD}

To examine the issues raised above, a self-reported questionnaire survey was conducted. The targets were ISs enrolled at national universities in the Kanto Region of Japan. The survey was circulated from early June to early July 2017. A total of 210 ISs submitted their responses. Four incomplete questionnaires were eliminated and the remaining 206 questionnaires were analyzed.

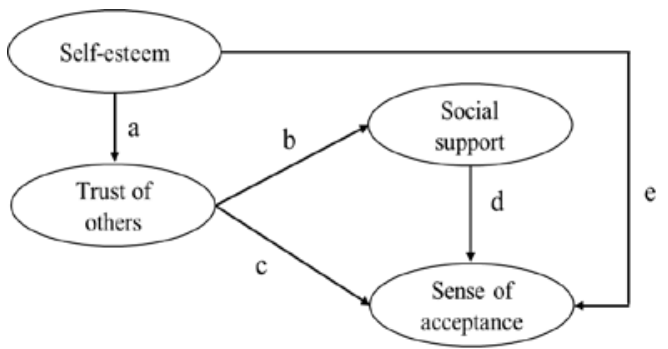

Fig. 1. The analyzed model.

The questionnaire included three parts-Part A, Part B and Part C. The content in each part was as follows:

Part A gathered personal information which included demographic data (e.g., gender, age, nationality and academic standing); length of stay in Japan; Japanese language learning history; level of Japanese language ability (score and level from the Japanese Language Proficiency Test, and self-evaluation of Japanese language proficiency in reading, listening, speaking and writing as compared to an adult native Japanese speaker, reported as a percentage); English language ability (score on TOEFL-iBT, TOEIC, and self-evaluation of English language proficiency in reading, listening, speaking, and writing as compared to an adult native English speaker, reported as a percentage); living situation; experience with/frequency of doing part-time jobs, and so on (see Table I for details).

Ten items were used to measure social skills. Two items were used to measure attitude (level of liking) toward general Japanese students (JSs) [9]. Ten additional items measured self-esteem [15] (Table II) and six items measured generalized trust [16] (Table III). Respondents were asked to use a five-point scale (“5. Strongly agree”; "3. Neither”; “1. Strongly disagree") in responding to each of the items.

Part B addressed the ISs' social support received from others. Twenty-nine items were chosen from [10] to measure support. Items 1-27 were originally used to measure the social support received by Chinese students in Japan; items 28 and 29 were revised in order to match the current situation of ISs in Japan. Respondents were also asked whether they received social support from each of three specific groups: Japanese people, same-language speakers, and other different-language speakers (Table IV).

Part C followed [17] to measure the individual's feeling of acceptance in Japan, using a five-point scale ("5. Strongly agree”; “3. Neither”; “1. Strongly disagree”) (Table V).

\section{RESULTS}

\section{A. Descriptive Results}

Table I reports the demographic details of the 206 respondents included in the study. Over $70 \%$ were graduate students, which is consistent with prior national survey results [18]. The top three nationalities were Chinese (including students from Hong Kong), Indonesian and South Korean, which was also similar to national survey results. The average length of stay in Japan was 26 months; the average length of Japanese language study was 39 months, which was also similar to previous studies, including [9]. Over one third of the respondents had passed the Japanese Language Proficiency Test (JLPT) Level 1, indicating that this group had a high level of Japanese language proficiency. As Table I shows, more than $40 \%$ had received scholarships, over half of which were from the Japanese government (MEXT).

A series of $t$-tests (independent samples) were conducted to determine whether there were gender differences in language ability, history of stay in Japan, or history of learning the Japanese language ${ }^{1}$. The tests revealed

${ }^{1}$ Japanese Language Proficiency was calculated as follows: (a) For ISs who had passed JLPT-L1/N1, the calculation was L1 score/400 or N1 score/180 (The total score for L1 is 400, while for N1 it is 180); (b) For ISs who had passed JLPT-L2/N2, the calculation was L2 score/400 x .08 or N2 score/180 x .08 (The L2/N2 level is approximately $80 \%$ of L1/N1); (c) For 
significant gender differences for history of learning the Japanese language (males vs. females: 32.21 vs. 47.61, $t$ $(203)=2.70, p<.01)$ and Japanese language proficiency (males vs. females: $t(203)=2.83, p<.01)$. Female ISs appeared to have a longer history of learning the Japanese language and a higher level of Japanese language proficiency.

\section{B. Internal Reliability for Each Scale}

TABLE I: STUDENT INFORMATION

\begin{tabular}{|c|c|}
\hline Gender ratio & Female: $47.6 \%$ \\
\hline Age (in years) & $25.3(S D=4.05$; range: $19-39$ years $)$ \\
\hline Academic standing: & $\begin{array}{l}\text { Undergraduate: } 23.3 \% \quad \text { Master course: } 56.8 \% \\
\text { Ph.D. course: } 17.0 \% \text {; Research students: } 2.4 \% \\
\text { Others: } 0.5 \%\end{array}$ \\
\hline $\begin{array}{l}\text { Nationalities } \\
\text { (Top 3) }\end{array}$ & $\begin{array}{l}\text { Chinese: } 56.8 \% \\
\text { South Korea: } 6.3 \% \text {; }\end{array}$ \\
\hline $\begin{array}{l}\text { History of stay in } \\
\text { Japan: }\end{array}$ & 26 months ( $S D=23.2$, range: $3-178$ months) \\
\hline $\begin{array}{l}\text { History of learning } \\
\text { the Japanese }\end{array}$ & 39 months ( $S D=41.4$, range: $0-252$ months) \\
\hline JLPT-N1/L1 holder & $35.0 \%$ \\
\hline $\begin{array}{l}\text { English language } \\
\text { abilities }^{2}\end{array}$ & $\begin{array}{l}\text { TOEFL-iBT: } 29.1 \% \quad \text { TOEIC: } 44.7 \% \\
\text { TOEFL-iBT \& TOEIC: } 1.0 \% \\
\text { IELTS: } 10.7 \% \quad \text { Other: } 1.5 \% \\
\text { Not take any: } 13.0 \%\end{array}$ \\
\hline Living situation & $\begin{array}{l}\text { Alone: } 75.2 \% \\
\text { With a family: } 10.7 \% \text {; } \\
\text { With Japanese students: } 2.4 \% \\
\text { Other: } 0.5 \%\end{array}$ \\
\hline Scholarship & $\begin{array}{l}\text { Yes: } 41.7 \% \text { (MEXT: } 55.9 \% \text {; } \\
\text { Private foundations in Japan: } 17.9 \% \\
\text { Other: } 26.2 \%\end{array}$ \\
\hline & No: $58.3 \%$ \\
\hline Part-time job daily & Yes: $37.9 \%$ \\
\hline
\end{tabular}

TABLE II: SELF-ESTEEM: ITEMS AND MEAN SCORE

\begin{tabular}{lc}
\hline \hline \multicolumn{1}{c}{ Items } & Mean \\
\hline 1. I am at least as valuable a person as most people. & 4.23 \\
2. I have various good qualities. & 4.10 \\
3. I always think that I am a loser.* & 3.85 \\
4. I am able to do things as well as most people. & 4.03 \\
5. I do not have much to brag about.* & 3.32 \\
6. I am positive to myself. & 4.03 \\
7. In general, I am satisfied with myself. & 3.68 \\
9. I think that I am totally useless.* & 3.92 \\
10. I always make excuses for my thinking that I am a useless & 4.33 \\
\hline \multicolumn{2}{c}{$\alpha=.80$ (Note: *refers to reversal items) }
\end{tabular}

Tables II through $\mathrm{V}$ show the items for self-esteem, generalized trust, social support and sense of acceptance, respectively. Tables II, III and V give the average scores for self-esteem, generalized trust and sense of acceptance. From the results, overall self-esteem appeared to be high, as all of the average scores were higher than the median score of 3.00. The level of generalized trust and sense of acceptance were also quite high. Our calculation of Cronbach's $\alpha$ coefficients indicated a high level of internal reliability for all of our

ISs who had not taken JLPT, proficiency was calculated as (self-evaluation percentage of listening + speaking + reading + writing)/400.

${ }^{2}$ As TOEFL and TOEIC have different standards, the English ability was calculated as follows: (a) For a TOEIC score over 950, TOEIC score/10 + 8; for a TOEIC score of 901-950, TOEIC score/10+4; for a TOEIC score of 851-900, TOEIC score/ $10+3$, and so on; (b) For those who did not take any test, proficiency was calculated as (self-evaluation percentage of listening + speaking + reading + writing)/ 400 . scales. Given this result, we used the score for each scale in our analysis. Before initiating our structural equation modeling (SEM) analysis, we conducted $t$-tests (independent samples) to determine whether there were any gender differences for the variables included here. None were detected.

\section{TABLE III: TRUST OF OTHERS: ITEMS AND MEAN SCORE}

\begin{tabular}{lc}
\hline \multicolumn{1}{c}{ Items } & Mean \\
\hline $\begin{array}{l}\text { 1. In general, I think that people are reliable. } \\
\text { 2. Based on my experiences so far, I think that others are } \\
\text { reliable to some extent. }\end{array}$ & 3.59 \\
$\begin{array}{l}\text { 3. Usually, if the situation permits, people would want to be } \\
\quad \text { honest and sincere when interacting with each other. }\end{array}$ & 3.90 \\
$\begin{array}{l}\text { 4. I think that I am able to keep my current relationship of } \\
\quad \text { trust even if there is something affecting it. }\end{array}$ & 3.81 \\
$\begin{array}{l}\text { 5. There are specific persons whom I can trust in my actual } \\
\quad \text { life. }\end{array}$ & 4.36 \\
$\begin{array}{l}\text { 6. I feel that I can meet trustworthy people even in the } \\
\text { absence of impossible in my future life. }\end{array}$ & 4.03 \\
\hline$\alpha=.83$ & \\
\hline \hline
\end{tabular}

C. Social Support Received from Japanese People, SameLanguage Speakers and Other Different-Language Speakers

Table IV shows the ISs' social support received from the various sources: Japanese people, same-language speakers and other different-language speakers. Results indicate that participants received material, psychological, directive, and informatics support from Japanese people in the area of research/study, as well as psychological support in the area of interpersonal relationships and directive support in the area of environment/culture. Perhaps not surprisingly, they received most of their social support—of all four types in all four areas-from same-language speakers, while they received the least social support from other different-language speakers.

\section{Relationship between Self-esteem, Generalized Trust, Social Support and SOA}

Prior to analyzing the possible causal relationships among the key variables, we examined correlations for all the variable pairs. Table VI shows the significant correlations. According to our results, female respondents had a longer history of learning the Japanese language and a higher Japanese language proficiency than the males in the study. Additionally, we found that ISs with higher levels of Japanese language proficiency received more social support from Japanese people, while those with higher levels of English language proficiency received more social support from other different-language speakers. Moreover, higher levels of self-esteem correlated to higher levels of generalized trust, while liking of general JSs, self-esteem, generalized trust, social support (from Japanese people, same-language speakers and other different-language speakers) all had positive correlations with SOA.

\section{E. Analysis of Causal Relationship}

Before conducting our structural equation modeling (SEM) analysis, it was necessary to determine which factor(s) influenced SOA. Based on the results of our correlation analysis, a multiple regression analysis was conducted using age, history of stay in Japan, liking of general JSs, Japanese and English proficiency, self-esteem, 
and social support from Japanese people, same-language speakers and other different-language speakers as independent variables. Results showed that liking of general JSs and self-esteem, along with history of stay in Japan and social support received from Japanese people and same-language speakers all had significant positive effects on SOA (Fig. 2).

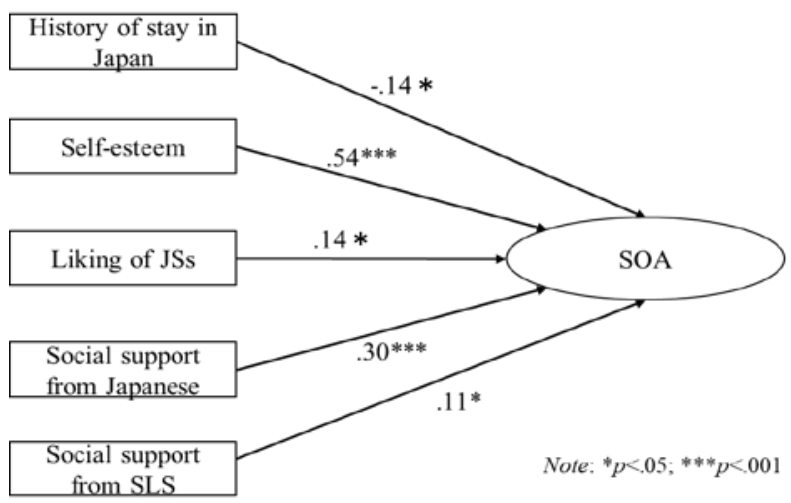

Fig. 2. Results of multiple regression analysis.

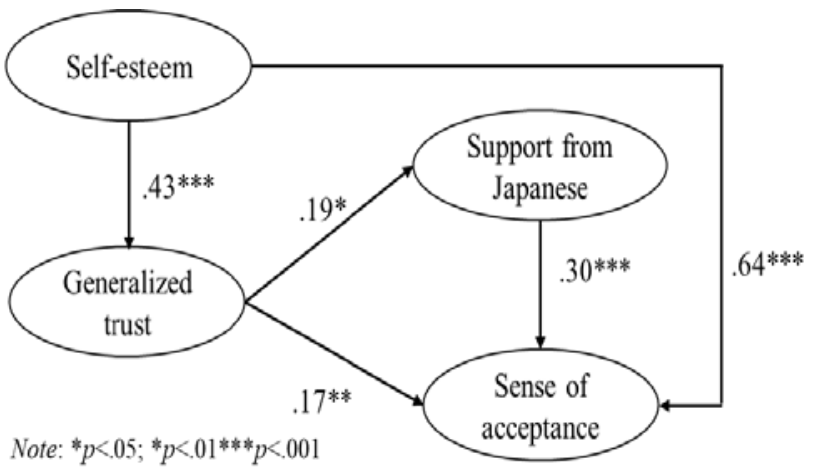

Fig. 3. Results of SEM analysis (Japanese people).

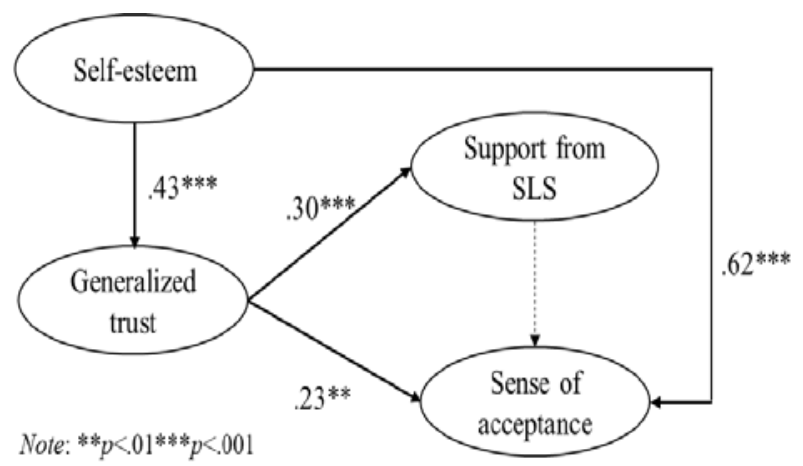

Fig. 4. Results of SEM analysis (same-language speakers).

We then conducted the SEM analysis described in Fig. 1. In order to compare the effects of social support from Japanese people with the effects of social support from same-language speakers, we examined two versions of the model. Results are shown in Fig. 3 and Fig. 4. As the figures show, we found both similarities and differences between the two models. In both cases, (a) self-esteem had strong direct effects on SOA, and (b) self-esteem had strong positive effects on the generalized trust of others, which led to more social support and greater SOA. However, we found that social support from Japanese people had strong positive mediating effects on SOA, whereas no similar effects were found for social support from same-language speakers.

\section{DISCUSSION}

\section{A. Main Findings}

The present study investigated the relationship between self-esteem, generalized trust of others, social support (from Japanese people, same-language speakers and other different- language speakers) and the sense of acceptance (SOA) felt by international students (ISs) in Japan. The results indicated that ISs received most of their social support from same-language speakers, followed by social support from Japanese people; they received the least social support from other different-language speakers. Although the results of multiple regression analysis showed that social support from Japanese people and same-language speakers had significant effects on SOA, the SEM analysis indicated that only social support from Japanese people had strong positive effects on raising the sense of acceptance among study participants. These results reconfirmed the implications of previous studies [7] [8].

The ISs' generalized trust of others had both positive effects on their receiving social support from Japanese people and on their SOA. Compared to its direct effects, the indirect effects associated with social support from Japanese people had much larger effects on SOA. As [1] [2] [19] suggested, people with higher levels of social intelligence are able to maintain a higher level of generalized trust. This implies that raising the social intelligence of ISs would be helpful in raising their level of generalized trust, thus enhancing their ability to communicate with more Japanese people, which, in turn, should lead to more social support and a greater ability to adapt to Japanese society.

This study also points out the important effects of self-esteem on receiving social support from Japanese people and raising SOA. In related studies, [13] found that for ISs coming from Western countries self-esteem is an important factor in seeking social support, while [20] suggested that different types of social support from different social networks may have different effects on cultural adaptation. The present study examined various processes and effects. As Fig. 3 shows, the direct effects of self-esteem on SOA was measured as .64, while its indirect effects through generalized trust and social support were much larger $(.43+.19+.30=.92)$. This suggests that improving self-esteem will not only be helpful to ISs in improving their intercultural adaptation, but also in forming close relationships with strangers, who can provide various kinds of social support that can further facilitate intercultural adaptation. This latter effect would seem to be especially important in the more open society that is likely to emerge in the future [1].

\section{B. Limitations and Future Research}

As previous studies (e.g., [6] and [21]) have suggested, the impact on SOA of perceived cultural distance and social support may be different depending on cultural background. However, in Japan, over $90 \%$ of the ISs are from Asia, with over $60 \%$ Chinese [18]. This lack of diversity makes it extremely difficult to compare perceived cultural distance and social support across a broad range of cultural backgrounds. In this sense, it would be desirable for future research to compare the implications of the present study with comparable studies from other countries. 
TABLE IV: SOCIAL SUPPORT RECEIVED BY ISS IN JAPAN

\begin{tabular}{|c|c|c|c|c|}
\hline $\begin{array}{l}\text { Area } \\
\text { Types }\end{array}$ & Research/Study & Interpersonal Relationship & Emotional & Environment /Culture \\
\hline Material & 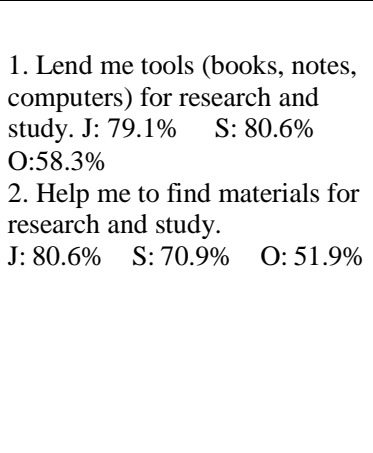 & $\begin{array}{l}\text { 10. Create opportunities and } \\
\text { make places for me to talk } \\
\text { with others. } \\
\text { J: } 60.7 \% \quad \text { S: } 76.7 \% \\
\text { O: } 43.2 \%\end{array}$ & $\begin{array}{l}\text { 16. Invite me to go outside } \\
\text { and have dinners when I } \\
\text { feel depressed/ have } \\
\text { troubles/feel lonely } \\
\text { J:33.5\% S:76.7\% } \\
\text { O:35.0\% }\end{array}$ & 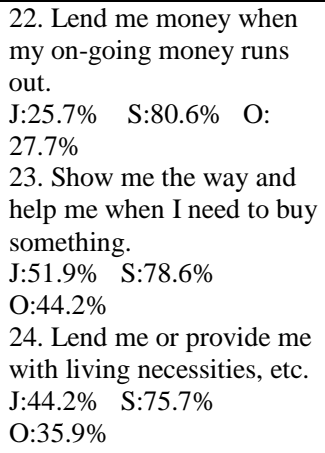 \\
\hline $\begin{array}{l}\text { Psychologica } \\
\text { l }\end{array}$ & 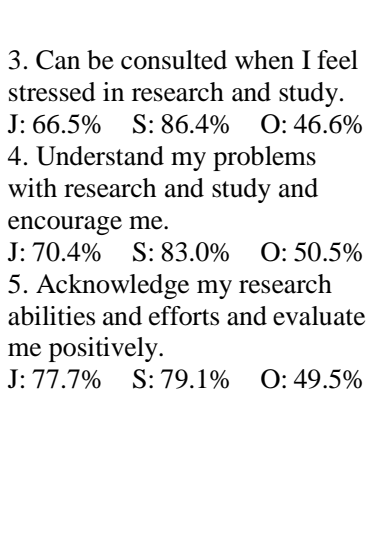 & 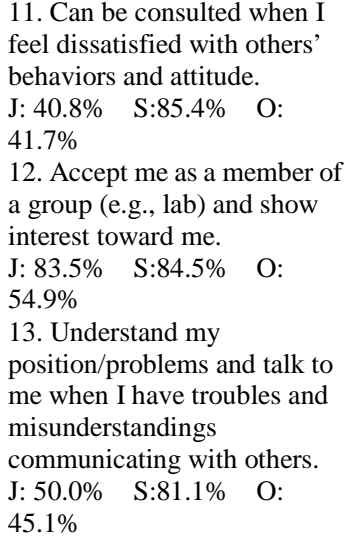 & $\begin{array}{l}\text { 17. Can be consulted and } \\
\text { listen to me when I feel } \\
\text { depressed/ have } \\
\text { troubles/feel lonely. } \\
\mathrm{J}: 40.3 \% \text { S:83.0\% O: } \\
36.9 \% \\
\text { 18. Stay with me when I } \\
\text { feel lonely. } \\
\mathrm{J}: 23.8 \% \text { S: } 71.4 \% \text { O: } \\
29.1 \% \quad \text { O } \\
\text { 19. Comfort me when I feel } \\
\text { frustrated or I am sad. } \\
\mathrm{J}: 40.8 \% \text { S: } 80.1 \% \text { O: } \\
36.4 \%\end{array}$ & $\begin{array}{l}\text { 25. Discuss with me and } \\
\text { understand my concerns } \\
\text { about Japanese culture, } \\
\text { customs and lifestyles. } \\
\mathrm{J}: 73.8 \% \text { S:77.7\% O: } \\
47.1 \% \\
26 \text {. Understand me through } \\
\text { discussions when there are } \\
\text { differences in our values. } \\
\mathrm{J}: 63.1 \% \text { S:83.0\% O: } \\
51.0 \% \quad\end{array}$ \\
\hline Directive & 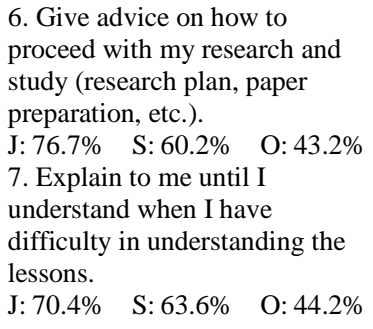 & $\begin{array}{l}\text { 14. Give me advice on my } \\
\text { behaviors/attitudes when } \\
\text { communicating with others } \\
\text { J: } 54.4 \% \quad \text { S: } 78.6 \% \quad \text { O: } \\
41.7 \%\end{array}$ & $\begin{array}{l}\text { 20. Give advice when I } \\
\text { have troubles. } \\
\text { J:64.1\% S: } 84.5 \% \\
\text { O: } 46.6 \% \\
21 \text {. Tell me good ways to } \\
\text { solve problems. } \\
\text { J:56.3\% S: } 80.1 \% \\
\text { O:47.1\% }\end{array}$ & $\begin{array}{l}\text { 27. Correct my incorrect } \\
\text { Japanese in daily life. } \\
\text { J:73.8\% S: } 49.5 \% \\
\text { O: } 27.7 \%\end{array}$ \\
\hline Informatics & $\begin{array}{l}\text { 8. Provide information on } \\
\text { research/reports and talk to me } \\
\text { about their experiences. } \\
\text { J: } 75.2 \% \quad \text { S: } 78.6 \% \quad \text { O: } 49.5 \% \\
\text { 9. Contact me and provide } \\
\text { information on progress and } \\
\text { homework about the lessons } \\
\text { when I was absent from the } \\
\text { class. } \\
\begin{array}{lll}\mathrm{J}: 54.4 \% & \text { S: } 68.4 \% \quad \text { O: } 39.3 \%\end{array}\end{array}$ & $\begin{array}{l}\text { 15. Provide information on } \\
\text { others' behaviors, attitudes, } \\
\text { hobbies and preferences, etc. } \\
\text { J: } 61.2 \% \quad \text { S:81.6\% O: } \\
49.5 \%\end{array}$ & & $\begin{array}{l}\text { 28. Provide information } \\
\text { such as part-time jobs, } \\
\text { scholarships and job } \\
\text { hunting for international } \\
\text { students. } \\
\text { J:47.1\% S:66.5\% O: } \\
38.3 \% \\
\text { 29. Tell me important } \\
\text { information (e.g., tax } \\
\text { exemption) about living in } \\
\text { Japan. } \\
\text { J:49.0\% S:73.8\% O: } \\
35.9 \%\end{array}$ \\
\hline
\end{tabular}

Note: J refers to Japanese people, S refers to same-language speakers, O refers to other different-language speaker

TABLE V: SENSE OF ACCEPTANCE: ITEMS AND MEAN SCORE

\begin{tabular}{|c|c|}
\hline Items & Mean \\
\hline 1. I am accepted in most cases. & 4.04 \\
\hline 2. People trust me. & 4.00 \\
\hline 3. People understand me. & 3.65 \\
\hline 4. People feel pleased when I am there. & 3.64 \\
\hline 5. People recognize me in most cases. & 3.84 \\
\hline 6. I am cherished as much as everyone else. & 3.72 \\
\hline 7. People usually respond to me pleasantly. & 4.13 \\
\hline 8. There is someone who is kind to me. & 4.33 \\
\hline 9. I believe that most people will be hard on me.* & 3.66 \\
\hline
\end{tabular}


TABLE VI: CORRELATION BETWEEN EACH VARIABLE

\begin{tabular}{|c|c|c|c|c|c|c|c|c|c|c|c|c|c|}
\hline & 1 & 2 & 3 & 4 & 5 & 6 & 7 & 8 & 9 & 10 & 11 & 12 & 13 \\
\hline $\begin{array}{l}\text { 1. Gender } \\
\text { 2. Age } \\
\text { 3. Stay period in Japan } \\
\text { 4. Learning history of } \\
\text { Japanese } \\
\text { 5. Japanese proficiency } \\
\text { 6. English proficiency } \\
\text { 7. Liking of Japanese students } \\
\text { 8. Self-esteem } \\
\text { 9. Generalized trust } \\
\text { 10. Support from Japanese } \\
\text { 11. Support from } \\
\text { same-language speakers } \\
\text { 12. Support from other } \\
\text { language speakers } \\
\text { 13. Sense of acceptance }\end{array}$ & $\begin{array}{c}-.17^{*} \\
.19^{* *} \\
.19^{*}\end{array}$ & $\begin{array}{c}-.38^{*} \\
* \\
\\
\\
.15^{*}\end{array}$ & $\begin{array}{c}.38^{* *} \\
.33^{* *} \\
-.15^{*} \\
\\
.18^{*}\end{array}$ & $.52^{* *}$ & $-.30 * *$ & $.19 * *$ & $\begin{array}{l}.19^{* *} \\
.28^{* *} \\
.26^{* *}\end{array}$ & $\begin{array}{l}.27^{* *} \\
.18^{* *} \\
.56^{* *}\end{array}$ & $\begin{array}{l}.19^{* *} \\
.28^{* *}\end{array}$ & $.23^{* *}$ & $.14^{*}$ & $.22 * *$ & \\
\hline
\end{tabular}

Note: As "gender" is nominal scale, this study coded male as " 1 " and female as " 2 " when conducting analysis. ${ }^{*} p<.05$, ${ }^{* *} p<.01$.

\section{CONCLUSION}

Developing educational approaches that enhance the self-esteem and social intelligence of international students in Japan will improve their level of generalized trust, leading to more communication with native Japanese and an increase in the social support they receive from the Japanese people.

\section{ACKNOWLEDGMENT}

The author would like to thank all the students who responded to this questionnaire survey.

\section{REFERENCES}

[1] T. Yamagishi, The Structure of Trust: The Evolutionary Games of Mind and Society, Tokyo: Tokyo University Press, 1998.

[2] T. Yamagishi and M. Yamagishi, "Trust and commitment in the United states and Japan,” Motivation and Emotion, vol. 18, no. 2, pp. 129-166, June 1994.

[3] N. Hayashi, E. Ostrom, J. Walker, and T. Yamagishi, "Reciprocity, trust, and the sense of control: A cross-societal study,” Rationality and Society, vol. 11, no. 1, pp. 27-46, February 1999.

[4] T. Yamagishi, "The provision of a sanctioning system as a public good," Journal of Personality and Social Psychology, vol. 5, no. 1, pp. 110-116, July 1986.

[5] T, Igarashi, Y. Kashima, E. S. Kashima et al., "Culture, trust, and social networks,” Asian Journal of Social Psychology, vol. 11, pp. 88-101, February 2008.

[6] Y. Mahfud, C. Badea, M. Verkuyten, and K. Reynolds, "Multiculturalism and attitudes toward immigrants: The impact of perceived cultural distance," Journal of Cross-Cultural Psychology, vol. 48, no. 8, pp. 1-14, September 2017.

[7] T. Tanaka, Social Network and Social Skills of International Students, Nakanishiya: Kyoto, 2000.

[8] T. Tanaka, J. Takai, H. Minami, and T. Fujihara, “A study on the adjustment of international students in Japan (2): Implications of social network formation on newly arrived students," Studies in Culture and the Humanities at Hiroshima University, III, vol. 14, pp. 95-113, March 1992.

[9] S. Y. Ye, “The relationship between international students' social skills, social support networks and adaptation in Japan," International Journal of Culture and History, vol. 3, no. 2, pp. 148-156. June 2017.

[10] Y. H. Jou, "An attempt to construct a social support scale for Chinese students in Japan,” Japanese Journal of Social Psychology, vol. 8, no. 3, pp. 235-245, March 1993.

[11] Y. H. Jou, "Research on longitudinal changes in social support for Chinese students in Japan,” no. 43, pp. 135-139, 1994

[12] Y. H. Jou, "An examination of a causal model for received support and adjustment of Chinese students in Japan," Japanese Journal of Psychology, vol. 66, no. 1, pp. 33-40, 1995.
[13] K. Ishii, T. Mojaverian, K. Masuno, and H. S. Kim, "Cultural differences in motivation for seeking social support and the emotional consequences of receiving support: The role of influence and adjustment goals,” Journal of Cross-Cultural Psychology, vol. 48, no. 9, pp. 1442 -1456, September 2017.

[14] F. E. Ikiz and F. S. Cakar, "Perceived social support and self-esteem in adolescence,” Procedia Social and Behavioral Sciences, vol. 5, pp. 2338-2342, March 2010.

[15] M. Yamamoto, Y. Matsui, and Y. Yamanari, "The structure of perceived aspects of self," The Japanese Journal of Educational Psychology, vol. 30, no. 1, pp. 64-68, 1982.

[16] Y. Amagai, "The effect of trust on ego-identity of high school students," Japanese Journal of Educational Psychology, vol. 43, no. 4, pp. 364-371, 1995

[17] T. Sugiyama, "Are perceived being-accepted and perceived being-rejected the results or causes of depression? : A longitudinal study including tree research,” Journal of Yamanashi Eiwa College, vol. 3, pp. 9-16, December 2004.

[18] Japan Student Services Organization (JASSO). (2017). Result of an annual survey of international students in Japan 2017. [Online]. Available:

http://www.jasso.go.jp/about/statistics/intl_student_e/2017/_icsFiles/ afieldfile/2017/12/22/data17.pdf

[19] T. Yamagishi and M. Kikuchi, "Trust, gullibility, and social intelligence,” Asian Journal of Social Psychology, vol. 2, no. 1, pp. 145-161, April 1999.

[20] S. M. Croucher, "Social networking and cultural adaptation: A theoretical model," Journal of International and Intercultural Communication, vol. 4, no. 4, pp. 259-264, November 2011.

[21] I. E. Babiker, J. L. Cox, and P. M. Miller, "The measurement of cultural distance and its relationship to medial consultations, symptomatology and examination performance of overseas students at Edinburgh university," Social Psychiatry, vol. 15, pp. 109-116, September 1980

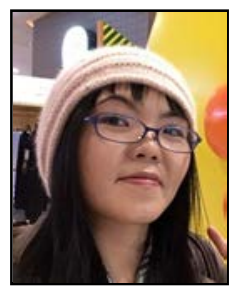

Shaoyu Ye was born in Canton, China, and is efficient in Chinese (both Cantonese and Mandarin), Japanese and English.

She received her Ph.D. (in philosophy) from Tokyo Institute of Technology (2015); master of social psychology from Ochanomizu University (Japan) (2010); master of Japanese language and literature from Shanghai Institute of Studies University (2006), and a bachelor of Japanese language and literature from South China Normal University (2003).

Dr. Ye is a pioneer researcher specializing in media usage's effects on interpersonal communication especially intercultural communication and social support networks. She was also a research fellow of the Japan Society for the Promotion of Science (JSPS) from 2014-15 (DC2 \& PD).

Dr. Ye is currently serving as an assistant professor at the Faculty of Library, Information and Media Science, University of Tsukuba in Japan. 